\title{
Intraocular pressure fluctuation in healthy and glaucomatous eyes: a comparative analysis between diurnal curves in supine and sitting positions and the water drinking test
}

\author{
Flutuação da pressão intraocular em olhos saudáveis e olhos glaucomatosos: análise comparativa \\ entre a curva tensional diária simplificada nas posições sentada, supina e o teste de sobrecarga hídrica
}

Rafael Ramos Calado $^{1}$, Emmerson Badaró ${ }^{1}$, Niro Kasahara ${ }^{2}$

\begin{abstract}
Purpose:To compare intraocular pressure (IOP) using the simplified daily tensional curve (SDTC) between supine and sitting positions in terms of peak levels and amount of fluctuation in both, glaucomatous and healthy subjects. The secondary endpoint was the comparison of these measures with those derived from the water drinking test (WDT).

Methods: Thirty patients with primary open-angle glaucoma (POAG) that were undergoing medical therapy and 30 healthy subjects were enrolled in this study. Each patient underwent a diurnal curve between 8 am and $4 \mathrm{pm}$. After lying down for 5 minutes, the IOP was measured with the Perkins tonometer. Patients were instructed to sit in the upright position for 5 minutes and the tonometry was repeated. At 4:15 pm, the WDT test was performed. Fluctuation was defined as the difference between the highest and the lowest IOP readings (range). The Student's t test was used to assess differences and a P value $<0.05$ was considered to be statistically significant. Results: The diurnal curve in the supine position demonstrated higher IOP average values (on average $3-4 \mathrm{mmHg}$ higher) compared to the sitting position $(p<0.0001)$ for both groups. IOP peaks were higher in the supine position; however, the IOP range was essentially the same between the three methods. Treated glaucomatous patients had higher IOP levels in all measurements, but the fluctuation for all tests performed appeared to be similar to that of healthy patients.

Conclusion: The data suggested that WDT can be used to estimate the diurnal IOP peak and fluctuation observed in the SDTC of the supine position for treated glaucomatous patients. Further studies can compare the possible correlation between the WDT results and those obtained from nocturnal supine measurements.

Keywords: Glaucoma, open-angle/physiopathology; Intraocular pressure/physiology; Circadian rhythm
\end{abstract}

\section{RESUMO}

Objetivo: Comparar a flutuação da pressão intraocular (PIO) nas posições sentada e supina, através da curva tensional diária simplificada (CTDS), durante o horário de consultório em pacientes saudáveis e com glaucoma primário de ângulo aberto (GPAA). O objetivo secundário foi comparar estas medidas com a flutuação da PIO verificada através do teste de sobrecarga hidrica (TSH) desses dois grupos.

Métodos: A amostra foi constituída por 60 indivíduos, divididos em dois grupos, 30 saudáveis e 30 glaucomatosos. Nenhum dos pacientes saudáveis usava medicação anti-glaucomatosa. Entre os portadores de glaucoma, todos estavam medicados. Foi realizada a CTDS (medidas realizadas entre 8:00 he às 16:00 h) na posição sentada e supina utilizando o mesmo tonômetro de Perkins. Imediatamente após a última medida (às 16:15 h), foi realizado o TSH. Flutuação foi definida como a diferença entre a maior e a menor medida de PIO. O teste t-Student foi usado para analisar as diferenças e 0 valor de $p<0,05$ foi considerado estatisticamente significante.

Resultados: Os picos de PIO foram sempre maiores na CTDS quando medidos na posição supina (em média $4 \mathrm{mmHg}$ maior) em pacientes saudáveis e pacientes glaucomatosos em tratamento, comparado a posição sentada $(p<0.0001)$. Pacientes glaucomatosos em tratamento apresentaram PIO mais altaem todas as medidas, porém a flutuação em todos os testes realizados foi semelhante comparada aos pacientes saudáveis. Aflutuação da PIO não apresentou diferença estatística entre os 3 métodos. Conclusão:Dados sugerem queo TSH pode serusado paraestimar o pico e aflutuação diurna da PIO na posiçãosupina na CTDS em pacientes glaucomatosos em tratamento. Estudos futuros poderão avaliar uma possível correlação entre os resultados do TSH e as medidas noturnas em posição supina.

Descritores: Glaucomadeânguloaberto/fisiopatologia; Pressão intraocular/fisiologia; Ritmo circadiano

\section{INTRODUCTION}

Recent studies ${ }^{(1-5)}$ have shown that the fluctuation in intraocular pressure (IOP) is an important factor in the progression of primary open-angle glaucoma (POAG). Treatment should include the reduction of IOP as well as the reduction of the risks of pressure peaks and elevated IOP fluctuation ${ }^{(1,6-11)}$.

To estimate this fluctuation, it is possible to use methods such as the daily tensional curve (DTC), the simplified daily tensional curve (SDTC), and the water drinking test (WDT).
The IOP values obtained during a period of 24 hours are important data that are needed to control and direct the treatment of the diseases. The IOP values obtained when measurements respect normal body positions (sitting during the day and supine during the night) will vary during the 24 hours of the day, while IOP peaks frequently occur during night hours ${ }^{(12)}$. Studies that have related the IOP increase with postural changes ${ }^{(5,13,14)}$ have associated this event with an increase in episcleral venous pressure ${ }^{(15)}$. They have concluded that this physiological mechanism is involved in the postural regulation
Funding: No specific financial support was available for this study.

Disclosure of potential conflicts of interest: None of the authors have any potential conflicts of interest to disclose.

Corresponding author: Rafael Ramos Caiado. Av. Higienópolis, 870 - São Paulo - SP - 01238-000 Brazil - E-mail: rrcaiado@hotmail.com

Approved by the Research Ethics Committee on human beings with the process number 106/06 
of IOP and may vary between individuals. This variation may help explain the weak IOP correlations found between the sitting and supine positions. According to Mosaed et al, the IOP data variations during both practice hours and night hours for non-treated glaucoma patients have been considered clinically relevant ${ }^{(12,16)}$.

A DTC gives a better estimate of an individual's IOP level and fluctuations than a single measurement during an office visit, but demands hospital admission where IOP can be measured over 24 hours. The DTC consists of taking IOP measurements every 3 hours, between 6 a.m. and midnight, to calculate the average pressure and the variability in the measurements. The DSTC is a similar method; however, these measurements are not performed during the night period. The WDT is a provocative test that consists of the ingestion of $1,000 \mathrm{~mL}$ of water in 5 minutes. The patient is asked to not ingest any liquid during the period after this. IOP is then measured immediately before the test and at every 15 minutes after the water ingestion, until the IOP returns to basal levels. This test calculates the time necessary for the eye to recuperate from liquid ingestion and is an indirect method to evaluate the peaks and fluctuation of IOP.

There have been concentrated efforts to determine some way of predicting IOP peaks. The WDT has been proposed as a practical method to predict the peak of the IOP diurnal tension curve but it had been considered to have inadequate diagnostic value in the past ${ }^{(17,18)}$. Still, previous studies have observed a correlation between the IOP peak in the diurnal tension curve and the WDT ${ }^{(19,20)}$.

John Liu et al found a strong correlation between IOP peak values obtained from measurements performed during the day and night hours in the supine position ${ }^{(13)}$. These authors concluded that IOP values obtained in the supine position during practice hours were more appropriate for the estimation of night IOP peaks than measurements made in the sitting position. Therefore, professionals should measure the IOP in both sitting and supine positions during practice examinations. Both values obtained will allow the ophthalmologist a broader insight towards the IOP peaks of that specific patient during all hours of the day.

Up to now, studies have compared the diurnal IOP peaks in the supine position with the nocturnal IOP peaks during sleep, but they have not evaluated the levels of fluctuation in these values. Therefore, the first objective of this study was to compare the IOP fluctuations in the sitting and supine positions during practice hours in healthy patients and in patients with POAG. The second aim of this study was to make a novel comparison of these measurements with the IOP fluctuations found using the water drinking test (WDT) for both groups.

\section{METHODS}

The design of this study was transversal and included healthy and glaucomatous patients that had visited the Ophthalmology Department of the Santa Casa de Misericórdia Hospital of São Paulo. The study was approved by the ethics committee of the same hospital.

All patients completed informed consent forms explaining the details about the research and the procedures to be performed.

\section{SAMPLe AND INCLUSION CRITERIA}

Sixty patients were selected and equally divided into two groups: healthy patients (G1), and glaucomatous patients (G2). Table 1 shows the distribution of patients according to age, gender, and race.

One eye of each patient was included in this study. If both eyes of the same patient were eligible, one was randomly selected.

Eyes with open angle glaucoma had to possess an open angle on gonioscopy and a glaucomatous optic disc with the presence of focal or diffuse neuroretinal rim thinning, focal or diffuse nerve fiber layer defects, a vertical cup-to-disc ratio greater than 0.6, or a vertical cup/ disc inter-eye asymmetry greater or equal to 0.2 not based on optic disc size asymmetry, which was associated with reproducible glaucomatous visual field defect based on Anderson's criteria(21). A visual
Table 1. Distribution of patients with normal eyes and those with POAG in terms of age, sex, and ethnicity

\begin{tabular}{lccc}
\hline & $\begin{array}{c}\text { Group of patients } \\
\text { with healthy eyes }\end{array}$ & $\begin{array}{c}\text { Group of patients } \\
\text { with POAG }\end{array}$ & $\boldsymbol{P}$ \\
\hline Age (in years) & $59.7 \pm 8.0$ & $61.5 \pm 5.6$ & $0.198^{*}$ \\
Sex & 14 & 12 & $0.456^{+}$ \\
Male & 16 & 18 & \\
Female & & & $0.136^{+}$ \\
Ethnicity & 22 & 18 & \\
Caucasian & 8 & 12 & \\
Black or of mixed race & & & \\
\hline
\end{tabular}

Source: glaucoma section of the Department of Ophthalmology at Santa Casa Medical School, São Paulo.

$\mathrm{POAG}=$ patients with primary open-angle glaucoma undergoing clinical treatment; ${ }^{*}=$ Student $t$-test $;{ }^{+}=$Chi-square test.

field defect was defined by the presence of a cluster of three or more non-edge points that had sensitivities with $p<0.05$; one of the points had a sensitivity with $p<0.01$, a corrected pattern standard deviation (CPSD) value with $p<0.05$, or a Glaucoma Hemifield Test (GHT) that was outside normal limits.

\section{Inclusion criteria for patients with glaucoma:}

- Patients with POAG undergoing clinical treatment (independent of the IOP value);

- Age over 40 years;

- No previous ophthalmological surgery (incisional or laser); and

- No other ocular disease.

\section{Inclusion criteria for healthy patients}

- Age over 40 years;

- Absence of ocular diseases;

- Symmetric or C/D ratio $<0.2$; and

- IOP $<22 \mathrm{mmHg}$.

All 30 patients with glaucoma were undergoing treatment for the disease. The distribution of medications used among patients are described in table 2 and included:

- Twenty-four patients were medicated using a beta-blocker;

- Three were medicated using a beta-blocker and a carbonic anhydrase inhibitor;

- Two were medicated using a beta-blocker and an alpha-agonist;

- One patient was medicated using a beta-blocker, an alpha-agonist, and a prostaglandin analogue.

\section{Procedures}

All patients had a complete ophthalmological evaluation, including medical history, visual acuity corrected by the Snellen chart, applanation tonometry using the Goldmann applanation tonometer, biomicroscopy, indirect gonioscopy using a Goldmann lens, indirect ophthalmoscopy, and computerized perimetry using the SITA STANDARD 24-2 strategy of the HFA 750 (Zeiss-Humphrey Systems, Irvine, CA, USA).

The IOPs were obtained using SDTC in the sitting and supine positions and using WDT in the sitting position.

The IOP measurements were made by the same examiner using a Perkins tonometer (MK2; Clement Clarke International, Essex, UK). One drop of $1 \%$ tetracaine chloridrate (Anestalcon, Alcon Laboratories, Fort Worth, TX, USA) and one drop of fluorescein sodium (Allergan, Irvine, CA, USA) were used for topical anesthesia and staining, respectively. Two consecutive IOP measurements were performed for 
each patient. A third IOP measurement was performed if a difference higher than $2 \mathrm{mmHg}$ was found between the first two measurements. The IOP value obtained was an average of the two closest IOP measurements.

The IOP Measurements for SDTC in the sitting and supine positions were performed during the following hours: 8 a.m., 10 a.m., 12 p.m., 2 p.m., and 4 p.m. Patients were initially instructed to lie down for 5 minutes before each supine IOP measurement was performed in the supine position. The WDT measurement was performed fifteen minutes after the last IOP measurement. For this evaluation, patients were instructed to drink $1000 \mathrm{~mL}$ of mineral water in 5 minutes; the IOP measurements were then made in the sitting position at baseline (at 4:15 p.m. ) and after 15, 30, 45, and 60 minutes.

\section{Statistical analysis}

Between groups, the Chi-square test was used to compare categorical values (ethnicity and gender) and the Student's T-test was used for continuous variables (IOP and age). All statistical testing was performed at a pre-set alpha of 0.05. The IOP fluctuation was defined as the difference between the lowest and the highest value for each test. The IOP peak was defined as the highest value measured for each test. Data obtained were presented as mean \pm standard deviation (SD). The statistical analysis was completed using the MedCalc Software bvba, v.13.3.1 (Ostend, Belgium).

\section{RESULTS}

The figure shows the fluctuation in IOP with SDTC in the sitting and supine positions for groups 1 and 2. Tables 3 and 4 show the comparison between the mean values of SDTC in the sitting and supine positions for each measured time, of the glaucomatous and healthy patients, respectively. The differences were found to be statistically significant between the two tests in both study groups $(p<0.0001)$.

Table 5 shows the differences in the mean IOP values from WDT between both groups. Glaucomatous patients had higher values than patients with healthy eyes at all times of the day.

Table 6 is a comparison chart showing the peak IOPs and fluctuations in IOP obtained with the three tests for both groups as well as their respective comparison values. For both groups, fluctuations in IOP did not vary in the three tests. In glaucomatous patients, pressure peaks were higher in the SDTC supine position and with WDT when compared to SDTC in the sitting position. There was no statistically significant difference in the SDTC supine position and WDT. In healthy patients, the pressure peak was higher in the SDTC supine position, followed by WDT and the SDTC sitting position.

\section{DISCUSSION}

The Advanced Glaucoma Intervention Study (AGIS)(22), investigated the risk factors associated with the progression of damage to the visual field using a point by point linear regression analysis of 401 patients with advanced POAG. Progression was observed in 30\% of eyes and large IOP fluctuations ( $p=0.0013$; probability ratio of 1.31; $95 \%$ confidence interval of 1.12-1.54) were associated with the worsening of the visual field ${ }^{(23)}$. When the linear regression analysis was repeated in eyes with and without a history of cataract extraction, the variation in IOP was the only variable that was consistently associated with progression of the visual field. The study concluded that large IOP variations increased the chances of progression damages in the visual field.

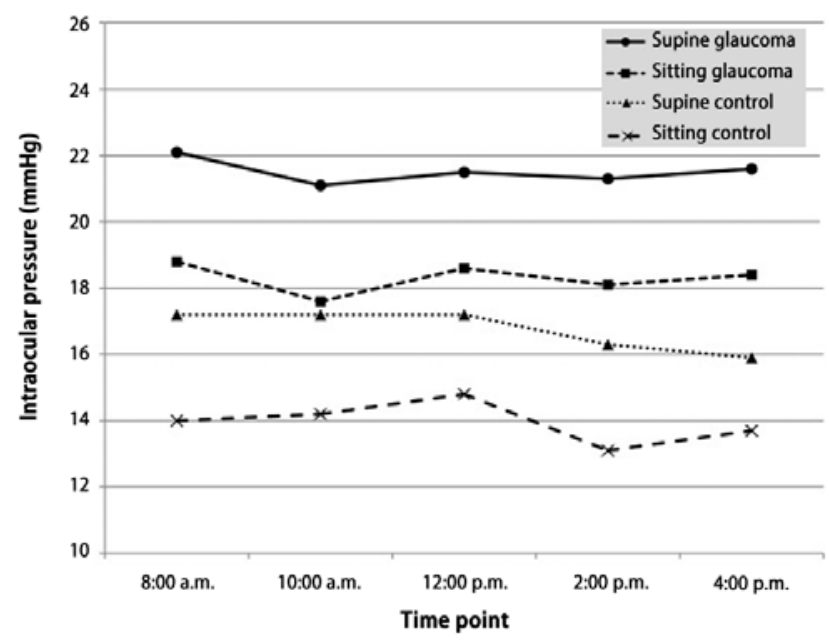

Figure. Diurnal pattern of Intraocular pressure (IOP) in the supine and sitting positions for primary open-angle glaucoma patients and normal subjects.

Table 2. Treated glaucomatous patient distribution according to medication protocol

\begin{tabular}{lc}
\hline Medications used & n (\%) \\
\hline Beta blockers & $24(80)$ \\
Beta blockers + carbonic anhydrase inhibitors & $3(10)$ \\
Beta blockers + alpha-agonists & $2(6.7)$ \\
Beta blockers+ alpha-agonists + prostaglandin analogs & $1(3.0)$ \\
\hline Total & $\mathbf{3 0 ( 1 0 0 . 0 )}$ \\
\hline
\end{tabular}


The present study showed that the diurnal curve between 8 a.m. and 4 p.m., performed in the supine position, presented higher absolute values for IOP (on average $4 \mathrm{mmHg}$ higher) compared to those in the sitting position $(p<0.0001)$ (Table 3 and Figure) which corroborated with previous studies ${ }^{(12,24)}$. After evaluating 198 patients with POAG, Hara et al evaluat observed a difference of $2.9 \mathrm{mmHg}$ between the pressure peaks of the SDTC in the sitting and supine positions $^{(24)}$. Liu et al studied 16 youths with healthy eyes and noticed an average difference of $4.5 \mathrm{mmHg}$ in the SDTC measurements in both positions. These same authors conducted a study with 21 individuals with healthy eyes with a mean age of $59.6 \pm 6.3$ years and detected an average increase of $4 \mathrm{mmHg}$ in the SDTC measured in the supine

Table 3. Mean IOP at each time point of SDTC for glaucoma patients

\begin{tabular}{lccc}
\hline Time & IOP (supine) & IOP (sitting) & P value \\
\hline 08 a.m & $22.1 \pm 3.5$ & $18.8 \pm 3.4$ & $<0.0001$ \\
10 a.m & $21.1 \pm 2.6$ & $17.6 \pm 2.8$ & $<0.0001$ \\
12 p.m & $21.5 \pm 3.0$ & $18.6 \pm 2.6$ & $<0.0001$ \\
02 p.m & $21.3 \pm 2.9$ & $18.1 \pm 2.7$ & $<0.0001$ \\
04 p.m & $21.6 \pm 3.0$ & $18.4 \pm 2.8$ & $<0.0001$ \\
\hline
\end{tabular}

Source: glaucoma section of the Department of Ophthalmology at Santa Casa Medical School, São Paulo.

$\mathrm{IOP}=$ intraocular pressure; $\mathrm{SDTC}=$ simplified daily tensional curve. $æ=0.05$.

Table 4. Mean IOP at each time point of SDTC for healthy subjects

\begin{tabular}{lccc}
\hline Time & IOP (supine) & IOP (sitting) & P value \\
\hline 08 a.m. & $17.2 \pm 2.8$ & $14.0 \pm 2.6$ & $<0.0001$ \\
10 a.m & $17.2 \pm 2.8$ & $14.2 \pm 2.3$ & $<0.0001$ \\
12 p.m & $17.2 \pm 2.9$ & $14.8 \pm 3.4$ & $<0.0001$ \\
02 p.m & $16.3 \pm 2.5$ & $13.1 \pm 2.9$ & $<0.0001$ \\
04 p.m & $15.9 \pm 2.4$ & $13.7 \pm 2.8$ & $<0.0001$ \\
\hline
\end{tabular}

Source: glaucoma section of the Department of Ophthalmology at Santa Casa Medical School, São Paulo.

$\mathrm{IOP}=$ intraocular pressure; $\mathrm{SDTC}=$ simplified daily tensional curve. $æ=0.05$

Table 5. Comparison of water drinking test between glaucoma patients and healthy subjects

\begin{tabular}{lccc}
\hline Time (minutes) & Healthy & Glaucoma & P value \\
\hline Basal average & $13.7 \pm 2.8$ & $18.4 \pm 2.8$ & $<0.0001$ \\
15 & $16.3 \pm 2.6$ & $20.4 \pm 3.6$ & $<0.0001$ \\
30 & $17.0 \pm 2.6$ & $20.8 \pm 3.3$ & $<0.0001$ \\
45 & $17.0 \pm 2.0$ & $22.0 \pm 3.4$ & $<0.0001$ \\
60 & $16.3 \pm 2.0$ & $21.7 \pm 3.3$ & $<0.0001$ \\
\hline
\end{tabular}

Source: glaucoma section of the Department of Ophthalmology at Santa Casa Medical School, São Paulo. position when compared to SDTC measured in the sitting position ${ }^{(14)}$. Our study revealed an average difference of $3 \mathrm{mmHg}$ between SDTC in the sitting and supine positions in individuals with healthy eyes (Table 4). This observation may be due to the possible increase in episcleral venous pressure and the subsequent increase in resistance in the aqueous humor ${ }^{(15,25-28)}$.

In the comparison between the pressure peaks measured using SDTC in the supine and sitting positions and the WDT, the results indicated that the highest measurement was obtained using SDTC in the supine position in both glaucomatous and healthy patients (Table 6). Using a modification in the diurnal IOP curve, Mosaed et al. observed that the magnitude of the nocturnal IOP peak in glaucomatous patients that were not in treatment could be estimated in the diurnal period by the IOP measurements in the supine position. In our study, we did not make a daily tensional curve during a 24-hour period, as did Mosaed et al. and Hara et al., including IOP measurements taken at night. A different tonometer was also used in the present study. Thus, we cannot correlate the nocturnal IOP peak with the IOP peak in the SDTC from the supine position. Nevertheless, we believed that the latter can be an approximate substitute for this measurement.

The fluctuation in intraocular pressure evaluated by the three methods did not show any difference between the groups (Table 6). It is possible that the absence of statistical difference between groups was due to the small sample analyzed. Still, the fluctuation in IOP in POAG patients was $3.5 \mathrm{mmHg}, 3.3 \mathrm{mmHg}$, and $4.5 \mathrm{mmHg}$, for SDTC in the supine position, SDTC in the sitting position, and WDT, respectively. For healthy patients, the fluctuation in IOP was $3.3 \mathrm{mmHg}, 3.1 \mathrm{mmHg}$, and $3.3 \mathrm{mmHg}$ for SDTC in the supine position, SDTC in the sitting position, and WDT, respectively.

Another difference in the present study compared to Mosaed et al and Hara et al was that the patients were already in treatment at the beginning of the study. According to other studies ${ }^{(29)}$, timolol maleate decreased IOP peaks. This interference may be the reason why the results between groups presented no statistically significant differences. However, we believe that a comparison between the fluctuations of patients treated with timolol maleate and untreated patients with POAG would be clinically relevant information. To perform a wash-out of our patients would not be considered ethical.

It has been well demonstrated in literature that the fluctuation in non-treated glaucomatous patients tended to be higher than in healthy subjects. An important fact observed in the present study was that although treated glaucomatous patients presented with higher IOP levels in all measurements, the fluctuations in all tests performed seemed to be similar to that of healthy patients. The results obtained in the present study may corroborate with other studies that have shown that the fluctuation in glaucoma patients under treatment were similar to that of healthy patients ${ }^{(30)}$.

As previously mentioned, diurnal IOP fluctuation is an important prognostic factor for glaucoma progression. The data from the present study showed that the diurnal fluctuation of the IOP measured by the SDTC in the sitting or supine positions was similar to that mea-

Table 6. Peak IOP and fluctuations in IOP for each test in healthy patients and patients with OAPG

\begin{tabular}{|c|c|c|c|c|c|c|}
\hline & Supine position & Sitting position & WDT & P1X2 & P1X3 & P2X3 \\
\hline Fluctuation (patients with OAPG) & $3.5 \pm 1.4$ & $3.3 \pm 1.0$ & $4.5 \pm 2.7$ & 0.582 & 0.298 & 0.129 \\
\hline Peak (patients with OAPG) & $23.5 \pm 3.3$ & $20.0 \pm 3.3$ & $22.5 \pm 4.4$ & 0.000 & 0.207 & 0.008 \\
\hline Fluctuation (patients with healthy eyes) & $3.3 \pm 1.8$ & $3.1 \pm 1.7$ & $3.5 \pm 1.6$ & 0.638 & 0.788 & 0.570 \\
\hline Peak (patients with healthy eyes) & $18.3 \pm 2.7$ & $15.3 \pm 3.0$ & $17.2 \pm 2.1$ & 0.000 & 0.026 & 0.005 \\
\hline
\end{tabular}

Source: glaucoma section of the Department of Ophthalmology at Santa Casa Medical School, São Paulo.

$\mathrm{IOP}=$ intraocular pressure; $\mathrm{OAPG}=$ patients with open-angle primary glaucoma undergoing clinical treatment; WDT= water drinking test; $æ=0.05 ; P 1 \times 2=$ value of $P$ for the difference between supine and sitting positions; $P 1 \times 3=$ value of $P$ for the difference between the supine position and WDT; $P 2 \times 3=$ value of $P$ for the difference between the sitting position and WDT. 
INTRAOCULAR PRESSURE FLUCTUATION IN HEALTHY AND GLAUCOMATOUS EYES: A COMPARATIVE ANALYSIS BETWEEN DIURNAL CURVES IN SUPINE AND SITTING POSITIONS AND THE WATER DRINKING TEST

sured by the WDT in both groups (healthy and glaucoma patients). In addition, the supine position IOP peak that had been shown to estimate the nocturnal peak ${ }^{(12)}$ was similar (statistically not different, as we can see in Table 6, P1X3) from the WDT peak. This information suggested that it would be possible to estimate the diurnal IOP fluctuation and the nocturnal peak by performing only the WDT which only takes about 60 min to be completed. Still, it is important to point out that this was only valid for glaucoma patients under treatment and additional studies with larger samples will be necessary to confirm the role of WDT in predicting these values.

\section{CONCLUSION}

Considering the limitations of the present study, the IOP measured by the SDTC in the sitting or in supine position was similar to that measured by the WDT in both groups (healthy and treated glaucomatous patients).

Although treated glaucomatous patients presented higher IOP levels in all measurements, the fluctuation in all tests performed seemed to be similar to that of healthy patients.

The data suggested that WDT can be used to estimate the diurnal IOP peak and fluctuation observed in the SDTC in the supine position of treated glaucomatous patients. Further studies should evaluate the possible correlation between WDT results to those obtained from nocturnal supine measurements.

\section{REFERENCES}

1. Asrani S, Zeimer R, Wilensky J, Gieser D, Vitale S, Lindenmuth K. Large diurnal fluctuations in intraocular pressure are an independent risk factor in patients with glaucoma. J Glaucoma. 2000;9(2):134-42

2. Zeimer RC, Wilensky JT, Gieser DK, Viana MA. Association between intraocular pressure peaks and progression of visual field loss. Ophthalmology. 1991;98(1):64-9.

3. Stewart WC, Chorak RP, Hunt HH, Sethuraman G. Factors associated with visual loss in patients with advanced glaucomatous changes in the optic nerve head. Am J Ophthalmol. 1993;116(2):176-81.

4. Stewart WC, Sine CS, LoPresto C. Surgical vs medical management of chronic open-angle glaucoma. Am J Ophthalmol. 1996;122(6):767-74.

5. Martinez-Bello C, Chauhan BC, Nicolela MT, McCormick TA, LeBlanc RP. Intraocular pressure and progression of glaucomatous visual field loss. Am J Ophthalmol. 2000; 129(3):302-8

6. Congdon N, Wang F, Tielsch JM. Issues in the epidemiology and population-based screening of primary angle-closure glaucoma. Surv Ophthalmol. 1992;36(6):411-23.

7. Klein BE, Klein R, Jensen SC. Open-angle glaucoma and older-onset diabetes. The Beaver Dam Eye Study. Ophthalmology. 1994;101(7):1173-7.

8. Realini T, Barber L, Burton D. Frequency of asymmetric intraocular pressure fluctuations among patients with and without glaucoma. Ophthalmology. 2002;109(7):1367-71.
9. Sacca SC, Rolando M, Marletta A, Macri A, Cerqueti P, Ciurlo G. Fluctuations of intraocular pressure during the day in open-angle glaucoma, normal-tension glaucoma and normal subjects. Ophthalmologica. 1998;212(2):115-9.

10. Wilensky JT. The role of diurnal pressure measurements in the management of open angle glaucoma. Curr Opin Ophthalmol. 2004;15(2):90-2.

11. Wilensky JT, Gieser DK, Dietsche ML, Mori MT, Zeimer R. Individual variability in the diurnal intraocular pressure curve. Ophthalmology. 1993:100(6):940-4.

12. Mosaed S, Liu JH, Weinreb RN. Correlation between office and peak nocturnal intraocular pressures in healthy subjects and glaucoma patients. Am jJ Ophthalmol. 2005; 139(2):320-4.

13. Liu JH, Zhang X, Kripke DF, Weinreb RN. Twenty-four-hour intraocular pressure pattern associated with early glaucomatous changes. Invest Ophthalmol Vis Sci. 2003;44(4): 1586-90

14. Liu JH, Kripke DF, Twa MD, Hoffman RE, Mansberger SL, Rex KM, et al. Twenty-four-hour pattern of intraocular pressure in the aging population. Invest Ophthalmol Vis Sci. 1999;40(12):2912-7.

15. Blondeau P, Tetrault JP, Papamarkakis C. Diurnal variation of episcleral venous pressure in healthy patients: a pilot study. J Glaucoma. 2001;10(1):18-24.

16. Susanna R, Jr., Vessani RM, Sakata L, Zacarias LC, Hatanaka M. The relation between intraocular pressure peak in the water drinking test and visual field progression in glaucoma. Br J Ophthalmol. 2005;89(10):1298-301.

17. Rasmussen $\mathrm{KE}$, Jorgensen $\mathrm{HA}$. Diagnostic value of the water-drinking test in early detection of simple glaucoma. Acta Ophthalmol. 1976;54(2 p):160-6.

18. Roth JA. Inadequate diagnostic value of the water-drinking test. $\mathrm{TBr} J$ Ophthalmol 1974;58(1):55-61.

19. Medeiros FA, Pinheiro A, Moura FC, Leal BC, Susanna R Jr. Intraocular pressure fluctuations in medical versus surgically treated glaucomatous patients. J Ocul Pharmacol Tther. 2002;18(6):489-98.

20. Miller D. The Relationship between diurnal tension variation and the water-drinking test. Am J Ophthalmol. 1964:58:243-6.

21. Anderson. D. Automated static perimetry. St Louis: Mosby-Year Book; 1992.

22. The Advanced Glaucoma Intervention Study (AGIS): 7. The relationship between control of intraocular pressure and visual field deterioration. The AGIS Investigators. Am J Opthalmol. 2000;130(4):429-40.

23. Nouri-Mahdavi K, Hoffman D, Coleman AL, Liu G, Li G, Gaasterland D, et al. Predictive factors for glaucomatous visual field progression in the Advanced Glaucoma Intervention Study. Ophthalmology. 2004;111(9):1627-35.

24. Hara T, Hara T, Tsuru T. Increase of peak intraocular pressure during sleep in reproduced diurnal changes by posture. Arch Ophthalmol. 2006;124(2):165-8.

25. Carlson KH, McLaren JW, Topper JE, Brubaker RF. Effect of body position on intraocular pressure and aqueous flow. Invest Opthalmol Vis Sci. 1987;28(8):1346-52.

26. Friberg TR, Sanborn G, Weinreb RN. Intraocular and episcleral venous pressure increase during inverted posture. Am J Ophthalmol. 1987;103(4):523-6.

27. Leith AB. Episcleral venous pressure in tonography. Br J Ophthalmol. 1963;47:271-8.

28. Sultan $\mathrm{M}$, Blondeau P. Episcleral venous pressure in younger and older subjects in the sitting and supine positions. J Glaucoma. 2003;12(4):370-3.

29. David R, Zangwill L, Briscoe D, Dagan M, Yagev R, Yassur Y. Diurnal intraocular pressure variations: an analysis of 690 diurnal curves. Br J Ophthalmol. 1992;76(5):280-3.

30. Sit AJ, Asrani S. Effects of medications and surgery on intraocular pressure fluctuation. Surv Ophthalmol. 2008;53(Suppl1):S45-55. 